\title{
AVALIAÇÃO TEMPORAL DA REGENERAÇÃO NATURAL EM UMA FLORESTA ESTACIONAL SEMIDECÍDUA SECUNDÁRIA, EM PIRENÓPOLIS, GOIÁS ${ }^{1}$
}

\author{
Fábio Venturoli² ${ }^{2}$ Jeanine Maria Felfili ${ }^{3}$ e Christopher William Fagg ${ }^{4}$
}

\begin{abstract}
RESUMO - A regeneração natural em ambientes florestais é dinâmica, variável no espaço e no tempo, e integra o ciclo de desenvolvimento das florestas. Em florestas estacionais tropicais, devido à sazonalidade climática, a regeneração natural depende principalmente da disponibilidade de umidade no solo, que afeta tanto os padrões de produção de sementes quanto a germinação, a sobrevivência e o desenvolvimento das plântulas. O objetivo deste estudo foi analisar a dinâmica da regeneração natural em uma floresta estacional semidecídua secundária, em Pirenópolis, Goiás, verificando as mudanças na composição florística de plântulas e arvoretas ao longo do tempo, e relacionando-as a fatores ambientais das parcelas por Análises de Correspondência Canônica (CCA). Os resultados indicaram plântulas mais dinâmicas do que arvoretas, em função principalmente do clima. Isso ocorreu devido à maior susceptibilidade das plântulas com relação ao estresse hídrico do solo e ao aumento da incidência de radiação solar e da temperatura na estação seca. Foi encontrada alta similaridade florística ( $\pm 50 \%)$ entre as populações da regeneração natural e a comunidade adulta, indicando estágio avançado de regeneração da floresta, com Índices de Diversidade superiores a 3,0 nats.indv-1 ${ }^{-}$. A CCA agrupou as espécies em função do gradiente ambiental de umidade e sombreamento versus cobertura do solo, posicionando próximas as espécies preferenciais de ambientes úmidos versus as preferenciais de ambientes mais secos de cerrado típico.

Palavras-chave: Sucessão florestal, Fatores ambientais e Cerrado.
\end{abstract}

\section{TEMPORAL EVALUATION OF NATURAL REGENERATION IN A SEMIDECIDUOUS SECONDARY FOREST IN PIRENÓPOLIS, GOIÁS, BRAZIL}

\begin{abstract}
The natural regeneration in forest environments is dynamic, variable in space and time and it is in the development cycle of forests. In seasonal tropical forests, due to seasonal climatic changes, natural regeneration depends mainly on availability of soil moisture, which affects patterns of seed production and germination, survival and development of seedling as well. The objective of this study was to analyze the dynamics of natural regeneration in a seasonal semideciduous secondary forest in Pirenópolis, Goiás, Brazil, by analyzing the changes in floristic composition of seedlings and small trees over time and relating them to environmental factors of plots in the study area by using Canonical Correspondence Analysis (CCA). The results indicated that seedlings were more dynamic than small trees mainly because of climate. This occurred because of the greater susceptibility of the seedling to soil water stress and the increase of solar radiation and temperature in the dry season. It was found a high floristic similarity ( $\pm 50 \%)$ among population of natural regeneration and the tree community, indicating an advanced stage of natural regeneration of the forest, with Diversity Index higher than 3.0 nats.indv-1. Canonical Correspondence Analysis grouped the species according to the environmental gradient of moisture and shade versus soil cover, placing near to each other, species of humid environments versus species of typical cerrado dry environments.
\end{abstract}

Keywords: Cerrado, Environmental factors and Forest succession.

\footnotetext{
${ }^{1}$ Recebido em 19.08.2009 e aceito para publicação em 14.04.2011.

${ }^{2}$ Universidade Federal de Goiás, UFG, Brasil. E-mail: <fabioventuroli@gmail.com>.

${ }^{3}$ Universidade de Brasília, UNB, Brasil. (In memoriam).

${ }^{4}$ Universidade de Brasília, UnB, Brasil. E-mail: >acaciafagg@gmail.com>.
} 


\section{INTRODUÇÃO}

O processo de regeneração natural em ambientes florestais é dinâmico, variável no espaço e no tempo e parte integrante do ciclo de desenvolvimento das florestas (RICHARDS, 1996). O conhecimento do potencial de regeneração de uma área e dos fatores condicionantes é essencial para o sucesso de projetos de restauração parcial ou total da vegetação em áreas degradadas ou no manejo florestal (HOSOKAWA et al., 1998).

Na dinâmica florestal, a fase madura é representada por um dossel fechado, formado pelos estratos superiores. No entanto, florestas estão expostas a perturbações que alteram a sua estrutura e composição. Árvores tornam-se senescentes, morrem, caem e criam clareiras, danificando algumas menores e beneficiando outras (RICHARDS, 1996). As clareiras ficam, então, completamente tomadas por herbáceas, lianas e árvores jovens, que, na medida em que crescem e se desenvolvem, restabelecem a fase madura (RICHARDS, 1996). A regeneração natural pode ser definida, então, como a restauração da fitomassa nas clareiras florestais à medida que o dossel alcança a maturidade (WHITMORE, 1991).

Independentemente do distúrbio que dá início à sucessão, morte de árvores mais velhas ou a queda de árvores por vento ou outras causas quaisquer, a abertura de clareiras e seus processos associados ocasionam fortes flutuações no ambiente luminoso do sub-bosque. Com isso, a dinâmica da regeneração natural depende dos requerimentos de luz pelas espécies que persistem no sub-bosque ou que germinam em resposta à formação da clareira (WHITMORE, 1989). Algumas espécies são heliófitas (intolerantes à sombra), desenvolvendo-se somente em ambientes de clareiras, e outras são tolerantes à sombra e suas plântulas são capazes de sobreviver e alcançar a maturidade mesmo sob um dossel fechado (SWAINE; WHITMORE, 1988; RICHARDS, 1996).

Naturalmente, há uma amplitude de sobrevivência de plântulas na sombra, representada por um contínuo de tolerância, como discutido por Augspurger (1984) e por Souza e Válio (2001). Além do mais, espécies juvenis tolerantes à sombra que sobrevivem no subbosque podem dominar a regeneração simplesmente por estarem lá no momento da abertura da clareira, reduzindo a vantagem competitiva das espécies pioneiras (FELTON et al., 2006), podendo, inclusive, ser determinante na formação de florestas monodominantes (MARIMON, 2005).

Em florestas estacionais tropicais, devido à sazonalidade climática, a regeneração natural depende principalmente da disponibilidade de umidade no solo (LIEBERMAN; LI, 1992; MCLAREN; MCDONALD, 2003a, b), que afeta tanto os padrões de produção de sementes quanto a germinação, a sobrevivência e o desenvolvimento das plântulas (KHURANA; SINGH, 2000). Além disso, a predominância de espécies caducifólias pode reduzir a cobertura foliar arbórea durante a estação seca (FELFILI, 2001) e provocar o dessecamento e a morte de sementes e plântulas, tanto pela ação direta da incidência da radiação solar como pela diminuição da umidade do solo (VIEIRA; SCARIOT, 2006). Nessas florestas, a dinâmica de clareiras pode não ser tão importante para a regeneração natural como em florestas tropicais pluviais, pois a sobrevivência de plântulas pode diminuir mesmo para as espécies heliófitas, por causa das altas temperaturas e pela baixa umidade do solo no período seco (MCLAREN; MCDONALD, 2003a, b.c).

Dessa forma, este trabalho teve o objetivo de estudar a dinâmica da regeneração natural em uma floresta estacional semidecídua secundária, em Pirenópolis, Goiás, relacionando-a ao clima, a características ambientais locais e ao estrato superior de árvores adultas, para identificar o estágio atual de regeneração da floresta e nortear ações de recuperação e manejo florestal nesses ambientes altamente ameaçados de extinção.

\section{MATERIAL E MÉTODOS}

A floresta em estudo localiza-se no município de Pirenópolis, Goiás (1549’S, 4859’W) e está a uma altitude média de 770 metros acima do nível do mar. É caracterizada como um fragmento de floresta estacional semidecídua (IBGE, 2004).

Segundo a classificação de Köeppen, o clima na região enquadra-se no tipo Aw, característico dos climas úmidos tropicais (A), com duas estações bem definidas: seca no inverno e úmida no verão (w) (NIMER, 1989). A temperatura média anual no município de Pirenópolis é de $22^{\circ} \mathrm{C}$, variando de $16^{\circ} \mathrm{C}$ a $34^{\circ} \mathrm{C}$, 
e a precipitação média anual é de $1800 \mathrm{~mm}$, com um período de estiagem que ocorre anualmente de maio a agosto (INMET, 2006).

O estudo da regeneração natural iniciou-se em abril de 2003, quando foram instaladas no fragmento florestal 16 parcelas de 25 x 30 m, adjacentes umas às outras. As parcelas foram inventariadas incluindo-se na amostragem os indivíduos do estrato lenhoso a partir de $5 \mathrm{~cm}$ de diâmetro na altura do peito. Com esses dados, foi efetuada uma análise indireta de gradientes pelo método DECORANA (Detrendend Correspondence Analysis), onde as parcelas se agruparam em função de um gradiente ambiental de umidade, desde uma área de floresta com influência ripária, até uma área de floresta em transição com um cerrado stricto sensu, nas partes mais altas do relevo. Em função da ordenação, foi adotado um delineamento experimental em blocos casualizados, com quatro blocos de quatro parcelas de 25 x 30 m cada uma.

O inventário da regeneração natural foi feito em subparcelas de 2 × 2 m e de $5 \times 5 \mathrm{~m}$, localizadas no canto superior esquerdo das parcelas de 25 x $30 \mathrm{~m}$. Nas subparcelas de 2 × $2 \mathrm{~m}$, todos os indivíduos de espécies arbóreas com altura total $(\mathrm{H})$ menor que $1 \mathrm{~m}(\mathrm{H}<1 \mathrm{~m})$ no momento das avaliações foram identificados, tiveram suas alturas medidas, e foram denominados plântulas. Nas subparcelas de $5 \times 5 \mathrm{~m}$, foram identificados e medidos todos os indivíduos com circunferência na altura do peito menor do que $9 \mathrm{~cm}(\mathrm{CAP}<9 \mathrm{~cm})$ e $\mathrm{H}>1 \mathrm{~m}$, medindo-se suas alturas, esses foram denominados de arvoretas.

As medidas de altura foram tomadas com o uso de uma régua de $1 \mathrm{~m}$ de comprimento e de uma vara graduada com limite máximo de $7 \mathrm{~m}$. Essa metodologia também foi utilizada por Felfili (1997) em avaliações da regeneração natural em matas de galeria no Brasil central, e é recomendada no Manual de Parcelas Permanentes para o bioma Cerrado e Pantanal (FELFILI et al., 2005).

Em outubro de 2003, foi feita a primeira avaliação da regeneração natural. As demais ocorreram em maio de 2004, agosto de 2005, outubro de 2006 e maio de 2007, cobrindo, assim, possíveis variações climáticas que poderiam influenciar a regeneração natural.

Para cada avaliação foram realizadas análises de riqueza, diversidade florística (Índice de Shannon-Wiener, H') e equabilidade (Índice de Pielou, J) (MAGURRAN, 1988; KENT; COKER, 1992; ZAR, 1999).
Foram avaliadas as mudanças na composição florística da regeneração natural ao longo do tempo, inclusive relacionando-as à pluviosidade local, medida na estação meteorológica de Pirenópolis. As mudanças nos índices de diversidade (H') foram testadas pelo teste $t$ modificado, como sugerido por Zar (1999).

Foram feitas também Análises de Correspondências Canônicas (TER BRAAK, 1986) entre a composição florística e os dados ambientais das parcelas, como declividade do terreno, cobertura do solo por vegetação e porcentagem de sombreamento na estação chuvosa.

A declividade do terreno foi estimada utilizando um Hipsômetro Haga, conforme recomendado por Imaña (1998), e seguindo metodologia descrita por Espartel e Lüderitz (1968).

A cobertura do solo foi estimada utilizando uma escala de cobertura aproximada à de Braun-Blanquet, consistindo de seis categorias: $<1 \%$ de cobertura; de 1 a $25 \%$ de cobertura; de 26 a 50\% de cobertura, de 51 a 75\%, de 76 a $99 \%$ e de $100 \%$ de cobertura (KENT; COKER, 1992). As avaliações foram feitas com o auxílio de um gabarito, quadrado, medindo 1 x 1 m na parte interna. As medições foram realizadas de forma aleatória dentro das subparcelas de avaliação da regeneração natural.

A porcentagem de sombreamento na estação chuvosa foi medida pela densidade de fluxo de fótons - DFF ( $\mu$ mol.m- ${ }^{2}$.s- $^{1}$ ) que atravessava o dossel. A DFF foi estimada com a utilização de sensores de quanta na faixa fotossinteticamente ativa. Os valores médios da DFF foram obtidos pela integração da curva diária de luz incidente no sub-bosque da floresta e a pleno sol, calculando-se a porcentagem de sombreamento pela razão entre os valores médios da DFF no interior da floresta e ao sol.

\section{RESULTADOS}

\subsection{Dinâmica das Populações de Plântulas e Arvoretas}

Nas avaliações da regeneração natural, foram encontradas plântulas de 60 espécies e arvoretas de 92 espécies. Porém, a distribuição do número de indivíduos pelas épocas de avaliação, em ambas as categorias, não foi uniforme, variando em função dos índices pluviométricos registrados na região (Figura 1).

As alterações no número de indivíduos ao longo do tempo foram acompanhadas de mudanças nas espécies, mas, apesar dessa variação, algumas espécies estiveram em todas as avaliações. Nas plântulas, 13\%

Revista Árvore, Viçosa-MG, v.35, n.3, p.473-483, 2011 


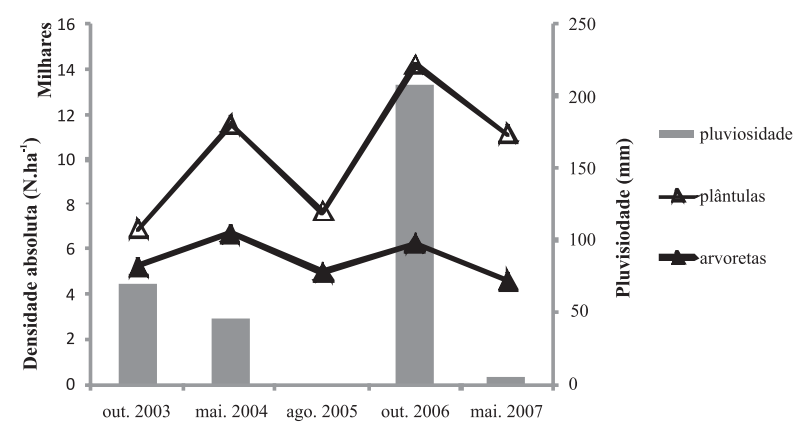

Figura 1 - Densidade absoluta de indivíduos (N.ha- ${ }^{1}$ ) nas populações de plântulas e arvoretas, em relação à pluviosidade total no mês de avaliação, na floresta estacional semidecídua secundária, em Pirenópolis, Goiás.

Figure 1 - Number of individuals (N.ha-1) in populations of seedlings and poles in relation to rainfall at a semideciduous secondary forest in Pirenópolis, Goiás, Brazil.

das espécies ocorreram em todas as avaliações: Alibertia macrophylla, Anadenanthera colubrina, Cardiopetalum calophyllum, Erythroxylum daphnites, Magonia pubescens, Protium heptaphyllum, Roupala montana e Simarouba versicolor; entre as arvoretas, $27 \%$ das espécies: A. macrophylla, Apuleia leiocarpa, Aspidosperma discolor, Astronium fraxinifolium, Plenckia populnea, Byrsonima crassifolia, C. calophyllum, Copaifera langsdorffii, Coussarea hydrangeifolia, Cupania vernalis, E. daphnites, Heisteria ovata, Himatanthus obovatus, Hymenaea courbaril, Luehea divaricata, Matayba guianensis, Myrcia rostrata, P. heptaphyllum, Qualea multiflora, Siparuna guianensis, Handroanthus aureus, Terminalia brasiliensis, Vatairea macrocarpa, Virola sebifera e Xylopia aromatica.

Essas espécies comuns às avaliações de cada categoria corresponderam a $43 \%$ do número total de plântulas contadas no período e a 70\% dos indivíduos entre as arvoretas. Três delas foram comuns a ambas as categorias em todas as avaliações, C. calophyllum, E. daphnites e P. heptaphyllum, estando presentes ainda como árvores adultas na floresta. Um total de 42 espécies da regeneração também estiveram no dossel da floresta, correspondendo a 29\% das espécies da comunidade florestal adulta.

Considerando a presença e ausência de espécies nas duas categorias da regeneração natural, por época de avaliação, o índice de similaridade florística de
Sorensen, indicou similaridade próxima de $50 \%$ entre plântulas e arvoretas, próxima de $70 \%$ dentro das arvoretas (entre avaliações) e de 50\% dentro das plântulas (entre avaliações) (Figura 2). Dentro das categorias da regeneração natural, houve ainda maior similaridade florística entre avaliações próximas temporalmente do que dentro de estações climáticas, assim como houve maior similaridade entre as arvoretas do que entre as plântulas (Figura 2).

Baseado na densidade das espécies de ocorrência comum às duas categorias de regeneração natural e às árvores adultas na floresta, foi verificado que houve correlação positiva e significativa entre as categorias, indicando que as espécies com maiores números de indivíduos como árvores também possuíam grande quantidade de indivíduos em regeneração [coeficiente de correlação linear de Spearman (rs), rs = 0,41 - árvores vs plântulas; rs = 0,71 - árvores vs.. arvoretas; e rs $=0,33$ - arvoretas vs. plântulas; $\mathrm{p}<0,03$ ].

Nas plântulas, os índices de diversidade de espécies de Shannon-Wiener variaram de 2,94 nats.indv-1 em outubro de 2003 a 3,17 nats.indv-1 em maio de 2004, não havendo diferença estatística entre nenhuma época de avaliação (teste $t, \mathrm{p}>0,05$ ). Em relação às arvoretas, os índices de diversidade de espécies variaram de 3,42 nats.indv- ${ }^{1}$ em outubro de 2003 a 3,68 nats.indv- ${ }^{1}$ em

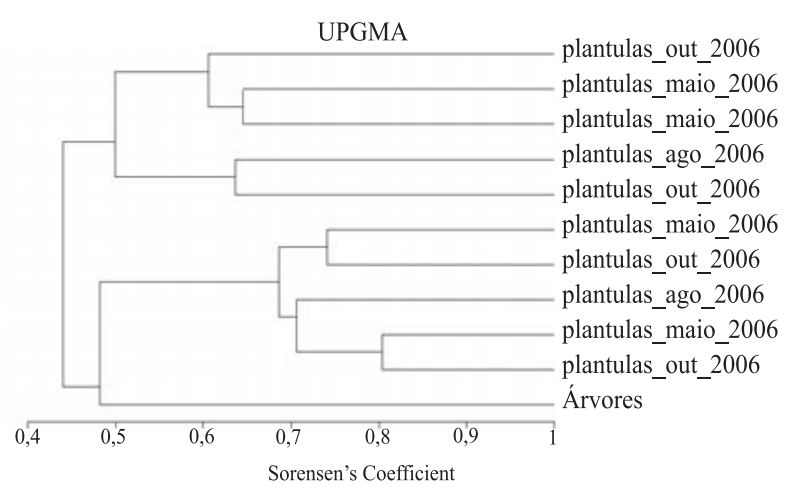

Figura 2 - Dendrograma de similaridade florística gerado pela técnica de UPGMA, com o Índice de Sorensen entre plântulas, arvoretas e árvores, por época de avaliação, na floresta estacional semidecídua secundária, em Pirenópolis, Goiás.

Figure 2-Floristic similarity dendrogram, generated by UPGMA technique, with Sorensen Index among seedlings, saplings and trees, for assessment of natural regeneration in the semideciduous secondary forest in Pirenópolis, Goiás, Brazil. 
outubro de 2006, apresentando diferença significativa entre essas duas avaliações e entre agosto de 2005 (3,46 nats.indv-1 $\left.{ }^{1}\right)$ e outubro de 2006 (3,68 nats.indv-1 $\left.{ }^{1}\right)$.

\subsection{Influência de Fatores Ambientais na Regeneração Natural}

A declividade do terreno nas parcelas variou de $40 \%$ a $85 \%$, e o percentual médio de sombreamento na estação chuvosa variou de 93,7\% a 97,5\%. Na cobertura do solo, as principais espécies presentes, além da regeneração natural, foram Paspalum sp. e Melinis minutiflora, e a cobertura variou de $25 \%$ a $85 \%$.

Quando analisada a composição florística das parcelas, por meio da ordenação por Correspondência Canônica, relacionando-a às características ambientais das parcelas, foram identificados agrupamentos em função do gradiente ambiental, posicionando juntas parcelas com características ambientais e florísticas similares (Figura 3).

Nas plântulas, primeiramente foram identificados dois grupos em função do percentual de sombreamento e da declividade do terreno versus o percentual de cobertura do solo. A maior parte das espécies (63\%) ficaram agrupadas nas parcelas com maiores percentuais de sombreamento e de declividade do terreno, agrupando-se próximas ao vetor de sombra e declividade (Figura 3): A. colubrina, E. daphnites, C. calophyllum, A. macrophylla, A. subincanum, S. versicolor e Handroanthus impetiginosus. Nesse grupo, encontram-se tanto espécies preferenciais de sombra (FELFILI et al., 2000) e que possuem afinidade com matas de galeria no Brasil central (SILVA JUNIOR et al., 2001) como as três primeiras; como espécies de floresta estacional em ambientes declivosos e mais férteis, como as duas seguintes; e espécies comuns entre as matas, o cerrado stricto sensu e o cerradão, como as duas últimas (MENDONÇA et al., 1998).

O segundo grupo de plântulas ficou relacionado a menor sombreamento, menor declividade e maior cobertura. As espécies posicionaram-se próximas do vetor de cobertura, no lado oposto aos vetores de sombra e declividade (Figura 3). Esse ambiente possui características que possivelmente influenciaram a presença de espécies com maior afinidade com o cerrado stricto sensu, como R. montana e Q. multiflora (FELFILI et al., 2001). Verificou-se ainda que não ocorreram espécies em regeneração nas parcelas que apresentavam os maiores percentuais de cobertura [variação de 65\% a $85 \%$ (parcelas 6, 10 e 11)].
Nas arvoretas, assim como nas plântulas, formou-se um grupo composto pelas parcelas que estiveram associadas às maiores declividades do terreno e a maior sombreamento, além de menores percentuais de cobertura. Nesse grupo, as espécies preferenciais foram A. discolor, A. leiocarpa, A. macrophylla, Bauhinia rufa, C. langsdorffii, $H$. courbaril, $M$. rostrata e Pouteria ramiflora, fortemente associadas (posicionadas mais próximas aos vetores de sombra e declividade) e Pouteria gardnerii, H. ovata, $P$. heptaphyllum, Vochysia tucanorum e Vochysia haenkeana, sob menor influência dos fatores ambientais (posicionadas um pouco mais distante dos vetores de sombra e declividade). Essas espécies também foram registradas em matas de galeria na região (SILVAJUNIOR et al., 2001), sendo a maioria espécies que ocorrem preferencialmente na sombra, como A. discolor, $A$. macrophylla, $M$. rostrata, $P$. ramiflora e $P$. heptaphyllum (FELFILI et al., 2000).

Ainda nas arvoretas, foi formado um segundo grupo de espécies em função da porcentagem de cobertura do solo. Com maior cobertura, verificou-se menor quantidade de espécies, somente $A$. fraxinifolium, E. daphnites, C. calophyllum, V. macrocarpa, R. viburnoides e Q. Multiflora (posicionadas próximas do vetor de cobertura). Essas espécies são de ocorrência mais comum em áreas de matas de galeria (FELFILI et al., 2000; SILVA JUNIOR et al., 2001), sendo V. macrocarpa e Q. multiflora espécies mais associadas ao cerrado stricto sensu (FELFILI et al., 2001).

\section{DISCUSSÃO}

\subsection{Dinâmica das Populações de Plântulas e Arvoretas}

O número de indivíduos por hectare encontrados na floresta estacional semidecídua secundária variou entre 6.875 e 14.219 para plântulas e 4.625 e 6.725 para arvoretas. Esses valores estão dentro da faixa de variação encontrada em outras formações florestais, sob condições climáticas semelhantes e com limites de inclusão na amostragem parecidos. Os resultados foram superiores aos encontrados por Campos e Landgraf (2001), em estudo de regeneração em mata subperenifólia com ocorrência de espécies de cerrado stricto sensu no sudeste do Brasil (3.770 indv.ha-1 a 4.510 indv.ha-1 ${ }^{1}$ ), e por Marra et al. (2007) (9.600 indv.ha-1 ${ }^{1}$, plântulas mais arvoretas) em floresta decidual de afloramento calcário

Revista Árvore, Viçosa-MG, v.35, n.3, p.473-483, 2011 
no Brasil central; e foram inferiores aos encontrados por Gonzaga et al. (2007) (44.000 indv.ha-1, plântulas mais arvoretas) também em florestas deciduais de afloramento calcário no Brasil central. Ficaram abaixo dos valores encontrados em matas de galeria no Brasil central por Felfili (1997) (entre 31.492 indv.ha- $^{1} \mathrm{e}$ 19.807 indv.ha- ${ }^{1}$ - plântulas; e entre 9.600 indv.ha- $^{1}$ e 5798 indv.ha- ${ }^{1}$ - arvoretas) em floresta de galeria preservada. Em mata de galeria perturbada, a densidade variou muito dentro das categorias (entre 23.083 indv.ha- ${ }^{1} \mathrm{e}$ 6.050 indv.ha-1 ${ }^{1}$ - plântulas; e entre 6.050 indv.ha-1 ${ }^{1}$ e 2.184 indv.ha- ${ }^{1}$ - arvoretas), ao longo de 24 anos, oscilando ao longo do tempo (OLIVEIRA; FELFILI, 2005).
Essa variação entre e dentro de formações florestais distintas, em condições climáticas semelhantes, indica que ambientes úmidos e preservados tendem a apresentar menor variação ao longo do tempo em relação aos perturbados. Esses últimos podem se assemelhar a ambientes mais secos de florestas estacionais devido, provavelmente, à maior abertura no dossel.

A maior densidade de plântulas em relação às arvoretas é característica normal da sucessão florestal, pois, sob competição, somente poucas plântulas sobrevivem e crescem até a idade adulta (PEET;CHRISTENSEN, 1987), conferindo a estrutura
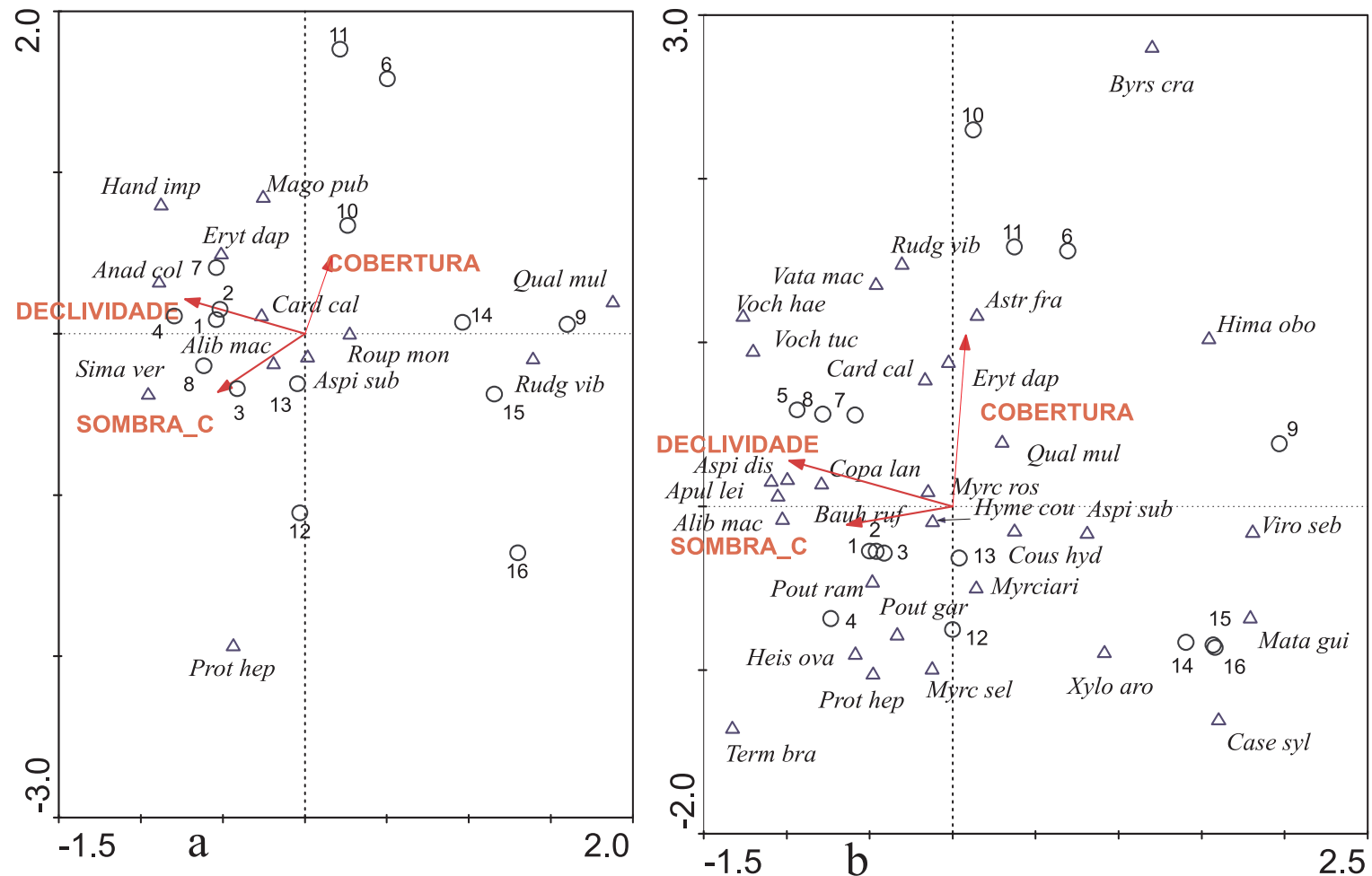

Figura 3 - Diagramas de ordenação por Análise de Correspondência Canônica (CCA) entre as populações de plântulas (a) e arvoretas (b) (espécies com mais de 9 indivíduos), na floresta estacional semidecídua secundária, em Pirenópolis, Goiás. As parcelas são identificadas pelos círculos, numerados de 1 a 16. As espécies são indicadas por triângulos e identificadas pelas iniciais de cada nome do binômio que se encontram por extenso no texto. As variáveis ambientais estão representadas nos vetores e são: COBERTURA (porcentagem de cobertura do solo), SOMBRA_C (porcentagem de sombreamento na estação chuvosa) e DECLIVIDADE (declividade do terreno, em porcentagem).

Figure 3 - Ordination diagrams by Canonical Correspondence Analysis - CCA among the populations of seedlings (a) and saplings (b) (species with more than 9 individuals) in semideciduous secondary forest in Pirenópolis, Goiás, Brazil. The plots are identified by circles, numbered from 1 to 16. The species are indicated by triangles and identified by the initials of each name of the binomial, which is found in text. Environmental variables are represented in vectors and they are: COBERTURA (percentage ground cover), SOMBRA_C (percentage of shading in the rainy season) and DECLIVIDADE (terrain slope in \%).

Revista Árvore, Viçosa-MG, v.35, n.3, p.473-483, 2011 
característica das florestas tropicais nativas em regime normal de sucessão que apresentam maior quantidade de indivíduos de pequeno porte em relação aos de maior porte na floresta (RICHARDS, 1996).

A alta similaridade florística entre e dentro das categorias da regeneração natural denota estabilidade temporal desse trecho da vegetação, que, apesar de heterogêneo em função dos gradientes ambientais, mantém a composição da flora ao longo do tempo.

A pequena variação ao longo do tempo entre os índices de diversidade de espécies também foi encontrada por Higuchi et al. (2006) em floresta estacional semidecídua, em Viçosa, MG, variando de 3,45 nats.indv-1 a 3,67 nats.indv-1 em oito anos, mas foi diferente do encontrado por Souza et al. (2002) em floresta ombrófila densa, oito anos após corte de cipós, que passou de 4,35 nats.indv-1 para 5,00 nats.indv-1 ${ }^{1}$, ou seja, a manutenção de índices semelhantes de diversidade neste estudo também denota estabilidade.

Este estudo confirmou ainda que as variações na riqueza e abundância de espécies na regeneração são muito intensas nas florestas estacionais em função das estações secas periódicas, conferindo maior recrutamento às estações chuvosas e maior mortalidade às estações secas, como apontado nos trabalhos de Lieberman e Li (1992), Gerhardt (1996), Marod et al. (2002), McLaren e McDonald (2003c) e Ceccon et al. (2004) em florestas estacionais em Gana, na Tailândia, na Jamaica e no México, respectivamente. Esse comportamento é considerado natural em florestas estacionais, afetando principalmente as populações mais jovens (plântulas), não havendo declínio nas populações ao longo do tempo, sob regime normal de sucessão florestal (GERHARDT; HYTTEBORN, 1992).

As variações anuais nos regimes de chuvas em florestas úmidas também influenciam o recrutamento e a mortalidade das espécies, ocorrendo maior mortalidade associada ao déficit hídrico, conforme estudos de Souza et al. (2002) em floresta ombrófila densa secundária de Minas Gerais, e de Metz et al. (2008) no Panamá, comparando florestas tropicais com diferentes variações no regime de chuvas.

As diferenças encontradas na abundância de espécies entre as plântulas e arvoretas ao longo do tempo (Figura 1; Kolmogorov-Smirnov, p < 0,001) confirmam os resultados já encontrados em outras florestas estacionais (LIEBERMAN; LI, 1992; MCLAREN; MCDONALD, 2003a, b; VIEIRA; SCARIOT, 2006). Plântulas são mais susceptíveis ao déficit hídrico sazonal por não possuírem raízes profundas capazes de captar água a maiores profundidades no solo (METZ et al., 2008). Os efeitos do déficit hídrico no período seco é exacerbado pelas altas temperaturas e altas intensidades de irradiação solar, levando ao dessecamento e morte das plantas (LIEBERMAN; LI, 1992; MCLAREN; MCDONALD, 2003a, b; VIEIRA; SCARIOT, 2006). Plântulas também estão mais sujeitas a danos físicos em decorrência da queda de galhos e árvores na floresta e por serem mais suscetíveis ao pisoteio por animais e ao ataque por patógenos (BATISTA; MAGUIRE 1998; ROLIN et al., 1999; MAROD et al., 2002). Podem também ser mais facilmente estranguladas ou quebradas por lianas (GERMING, 2001). Além disso, essas populações estão expostas ao impacto de outros fatores ambientais, como heterogeneidade do solo, microtopografia, pequenos distúrbios, herbivoria, e podem também sofrer a influência de fatores endógenos, como hábito de crescimento das espécies dominantes (RUSCH, 1992), tornando o padrão da comunidade muito dinâmico, pois podem atuar em todos os estágios da sucessão.

A maior susceptibilidade das plântulas ao ambiente foi refletida na distribuição das alturas das plantas em regeneração, que variou bastante ao longo do tempo, sugerindo atividades dinâmicas intensas, com mortalidade relacionada mais ao ambiente do que à competição. Ocorrendo o contrário nas arvoretas, que estariam sob maior competição entre si e com as árvores no dossel, mas que sobrevivem, em grande parte, às condições adversas impostas pelo período seco.

A relação entre a densidade de arvoretas por plântulas em comunidades florestais pode indicar a taxa de mudança entre as categorias de regeneração na floresta, e em comunidades clímax tende a ser constante ao longo do tempo, sugerindo que as perdas relacionadas à mortalidade somadas aos egressos às classes superiores são compensadas pelo ingresso e recrutamento nas classes inferiores, mantendo-se o estado de equilíbrio (O’HARA, 2002). Mas essa estrutura não foi encontrada na floresta em estudo, onde houve grande variação na relação entre a densidade de arvoretas por plântulas ao longo do tempo, variando de $41 \%$ a $76 \%$.

Revista Árvore, Viçosa-MG, v.35, n.3, p.473-483, 2011 
De certo modo, essa variação temporal na proporção de arvoretas para plântulas era esperada, demonstrando o estágio avançado de regeneração, mas não maduro, o que caracteriza, de certa forma, as florestas secundárias. Por outro lado, uma mata de galeria bem preservada no Brasil central apresentou taxas constantes entre arvoretas e plântulas ao longo do tempo, de $25 \%$ a 30\% (FELFILI, 1997).

\subsection{Influência de Fatores Ambientais na Regeneração Natural}

A maior concentração de espécies nas parcelas mais sombreadas e sob maior umidade também foi encontrada em estudos envolvendo tratamentos silviculturais, tanto em florestas estacionalmente secas (MCLAREN; MCDONALD, 2003b, c) na Jamaica como em florestas úmidas (KARIUKI et al., 2006) na Austrália. Em sítios sombreados, há tendência em encontrar maior densidade de plântulas em relação a sítios abertos, em decorrência de condições dessecantes nesses últimos (LIEBERMAN; LI, 1992). Estudos indicam que desbastes de refinamento do sub-bosque foram significativos no desenvolvimento da regeneração natural em floresta semidecídua na estação chuvosa, mas prejudiciais na estação seca, justamente por intensificar os efeitos da maior incidência de radiação solar na estação seca (GERHARDT, 1996; MCLAREN; MCDONALD, 2003b).

Apesar das tendências encontradas na associação de espécies aos fatores ambientais, principalmente, sombreamento e influência ripária. Deve-se lembrar que a Análise de Correspondência Canônica é uma análise direta de gradientes e que agrupa a composição florística aos fatores ambientais mensurados.

Discute-se ainda na literatura que, nas comunidades, os processos de recrutamento de plântulas são altamente estocásticos, dependendo da dispersão de sementes, produção de sementes, disponibilidade de sementes viáveis e ocorrência de pequenos microssítios adequados para a germinação (RUSCH, 1992), o que torna esses estudos fundamentais no entendimento do funcionamento desses ecossistemas, para melhor manejá-los e para promover a recuperação e a manutenção desses ambientes, inserindo-os no contexto do desenvolvimento regional sustentável a partir da utilização racional dos recursos florestais.

\section{CONCLUSÕES}

Esse estudo da regeneração natural comprovou que as populações de plântulas são mais dinâmicas do que as de arvoretas, variando em função da estacionalidade climática, como discutido na literatura.

Esta floresta secundária encontra-se em estágio avançado de regeneração, pois, em relação à composição florística, existiu similaridade entre as populações acima de 40\%. Inclusive em relação às árvores adultas, demonstrando que as espécies presentes no dossel também possuíam indivíduos em todas as fases da regeneração natural.

A constância de um grupo de espécies ao longo do tempo, compondo os estratos de regeneração e adulto denota estabilidade nesta floresta.

A presença de espécies de valor comercial madeireiro na regeneração, assim como no dossel, como $H$. courbaril, A. fraxinifolium, V. sebifera, C. langsdorffii, A. leiocarpa, A. discolor, V. haenkeana, V. tucanorum, Q. multiflora, $H$. impetiginosus e $A$. colubrina, ressalta o potencial de manejo dessa floresta.

\section{REFERÊNCIAS}

AUGSPURGER, C. K. Likght requirements of neotropical tree seedling: A comparative study of growth and survival. Journal of Ecology, v.72, n.3, p.777-795, 1984.

BATISTA, J. L. F.; MAGUIRE, D. A. Modeling the spatial structure of tropical forests. Forest Ecology and Management, v.110, p.293314,1998

CAMPOS, J. C.; LANDGRAF, P. R. Análise da regeneração natural de espécies florestais em matas ciliares de acordo com a distância da margem do lago. Ciência Florestal, v.11, n.2, p.143-151, 2001.

CECCON, E.; SÁNCHEZ, S.; CAMPOM, J. Tree seedling dynamics in two abandoned tropical dry forests of differing sucessional status in Yucatán, Mexico: a field experiment with $\mathrm{N}$ and $\mathrm{P}$ fertilization. Plant Ecology, v.170, p.277-285, 2004.

ESPARTEL, L.; LÜDERITZ, J. Caderneta de Campo. Porto Alegre: Globo, 1968. 655p. 
FELFILI, J. M. Dynamics of the natural regeneration in the Gama gallery Forest in central Brazil. Forest Ecology and Management, v.91, p.235-245, 1997.

FELFILI, J. M. Principais fisionomias do espigão mestre do São Francisco. In: FELFILI, J. M.; SILVA JÚNIOR, M. C. (Orgs.). Biogeografia do bioma cerrado: estudo fitofisionômico da Chapada do Espigão Mestre do São Francisco. Brasília: Universidade de Brasília, 2001. p.18-30

FELFILI, J. M.; CARVALHO, F. A.; HAIDAR, R. F. Manual para o monitoramento de parcelas permanentes nos biomas cerrado e pantanal. Brasília: Universidade de Brasília, Departamento de Engenharia Florestal, 2005. 55p.

FELFILI, J. M. et al. Desenvolvimento inicial de espécies de mata de galeria. In: RIBEIRO, J. F.; FONSECA,C. E. L.; SOUZA-SILVA J. C. (Eds.).Cerrado: caracterização e recuperação de matas de galeria. Planaltina: Embrapa, 2001.

FELFILI, J. M. et al. Recuperação de Matas de Galeria. Planaltina: Embrapa, 2000.

FELTON, A. et al. Vegetation structure, phenology, and regeneration in the natural and anthropogenic tree-fall gaps of a reducedimpact logged subtropical Bolivian forest. Forest Ecology and Management, v.235, p.186-193, 2006.

GERHARDT, K. Effects of root competition and canopy openness on survival and growth of tree seedlings in seasonal dry Forest. Forest Ecology and Management, v.82, p.33-48, 1996.

GERHARDT, K.; HYTTEBORN, H. Natural dynamics and regeneration methods in tropical dry forests - an introduction. Journal of Vegetation Science, v.3, p.361-364, 1992.

GERWING, J. J. Testing liana cutting and controlled burning as silvicultural treatments for a logged forest in the eastern Amazon. The Journal of Applied Ecology, v.38, n.6, p.1264-1276, 2001.
GONZAGA, A. P. D. et al. Padrões florísticos e estruturais da regeneração natural de dois remanescentes de floresta estacional decidual em Montes Claros, Norte de Minas Gerais. In: CONGRESSO NACIONAL DE BOTÂNICA, 58. 2007, São Paulo. Anais... São Paulo: 2007.

HIGUCHI, P. et al. Composição florística da regeneração natural de espécies arbóreas ao longo de oito anos em um fragmento de floresta estacional semidecidual, em Viçosa, MG. Revista Árvore, v.30, n.6, p. 893-904, 2006.

HOSOKAWA, R. T.; MOURA, J. B.; CUNHA, U. $S$. Introdução ao manejo e economia de florestas. Curitiba: Universidade Federal do Paraná, 1998.162p.

IMAÑA, J. E. Dasometria practica. Brasília, Universidade de Brasília, 1998. 112p.

INSTITUTO BRASILEIRO DE GEOGRAFIA E ESTATÍSTICA - IBGE. Mapa de Vegetação do Brasil. Rio de janeiro: 2004.

INSTITUTO NACIONAL DE METEOROLOGIA INMET. Normais Climatológicas. Disponível em <http://www.inmet.gov.br $>$ acessado em: 15 de janeiro de 2006 .

KARIUKI, M. et al. Regeneration changes in tree species abundance, diversity and structure in logged and unlogged subtropical rainforest over a 36-year period. Forest Ecology and Management, v.236, p.162-176, 2006.

KENT, M.; COKER, P. Vegetation description and analysis: a practical approach. London: Belhaven Press, 1992. 363p.

KHURANA, E.; SINGH, J. S. Ecology of seed and seedling growth for conservation and restoration of tropical dry forest: a review.

Environmental Conservation, v.28, n.1, p.39-52, 2000.

LIEBERMAN, D.; LI, M. Seedling recruitment patterns in a tropical dry forest in Ghana. Journal of Vegetation Science, v.3, p.375-382, 1992.

MAGURRAN, A. E. Ecological diversity and its measurement. London: Chapman and Hall, 1988.179p.

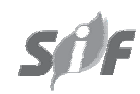

Revista Árvore, Viçosa-MG, v.35, n.3, p.473-483, 2011 
MARIMON, B. S. Dinâmica de uma floresta monodominante de Brosimum rubescens Taub. e comparação com uma floresta mista em Nova Xavantina-MT. 2005. 243f. Tese (Doutorado em Ecologia) - Universidade de Brasília, Brasília, 2005.

MAROD, D. et al. The effects of drought and fire on seed and seedling dynamics in a tropical seasonal forest in Thailand. Plant Ecology, v.161, p.41-57, 2002.

MARRA, D. M.; FELFILI, J. M.; PEREIRA, B. A. S. Fitossociologia da regeneração natural de uma floresta estacional decidual em afloramentos calcáreos na APA de Cafuringa, Distrito Federal, Brasil. In: CONGRESSO NACIONAL DE BOTÂNICA, 58., 2007, São Paulo. Anais. São Paulo: 2007.

MCLAREN, K. P.; MCDONALD, M. A. Coppice regrowth in a disturbed tropical dry limestone forest in Jamaica. Forest Ecology and Management, v.180, n.1, p.99-111, 2003a.

MCLAREN, K. P.; MCDONALD, M. A. Seedling dynamics after different intensities of human disturbance in a tropical dry limestone forest in Jamaica. Journal of Tropical Ecology, v.19, p. 567-578, 2003b.

MCLAREN, K. P.; MCDONALD, M. A. The effects of moisture and shade on seed germination and seedling survival in a tropical dry Forest in Jamaica. Forest Ecology and Management, v.183, n.1, p.61-75, 2003c.

MENDONÇA, R. C. et al. Flora vascular do cerrado. In: SANO, S. M.; ALMEIDA, S. P. (Eds.). Cerrado: ambiente e flora. Planaltina: Embrapa, 1998. p.89-166.

METZ, M. R. et al. Temporal and spatial variability in seedling dynamics: a cross-site comparison in four lowland tropical forests.

Journal of Tropical Ecology, v.24, n.1, p.9-18, 2008.

NIMER, E. Climatologia do Brasil. Rio de Janeiro: IBGE, Departamento de Recursos Naturais e Estudos Ambientais, 1989. 422p.
O’HARA, K. L. The historical development of uneven-aged silviculture in North America. Forestry, v.75, n.4, p.339-346, 2002.

OLIVEIRA, E. C. L.; FELFILI, J. M. Estrutura e dinâmica da regeneração natural de uma mata de galeria no Distrito Federal, Brasil. Acta

Botânica Brasílica, v.19, n.4, p.801-811, 2005.

PEET, R. K.; CHRISTENSEN, N. L. Competition and tree death. BioScience, v.37, n.8, p.586-595, 1987.

RICHARDS, P. W. The tropical rainforest: an ecological study. 2.ed. Cambridge, Cambridge University Press, 1996.

ROLIN, S. G.; COUTO, H. T. Z.; JESUS, R. M. Tree mortality and recruitment in the Atlantic Forest at Linhares (ES). Scientia Forestalis, v.55, p.49-69, 1999.

RUSCH, G. Spatial pattern of seedling recruitment at two different scales in a limestone grassland. Oikos, v.65, p.433-442, 1992.

SILVA JÚNIOR, M. C. et al. Análise da flora arbórea de matas de galeria no Distrito Federal: 21 levantamentos. In: RIBEIRO, J. F., FONSECA, C. E. L.; SOUZA-SILVA, J. C. (Eds.) Cerrado: caracterização e recuperação de matas de galeria/. Planaltina: Embrapa, 2001.

SOUZA, A. L.; SCHETTINO, S.; JESUS, R. M. Natural regeneration dynamics of a secondary dense ombrophylous forest, after vine cutting at Vale do Rio Doce S.A. Natural Reserve in Espírito Santo, Brazil. Revista Árvore, v.26, n.4, p.411-419, 2002.

SOUZA, R. P.; VÁLIO, I. F. M. Seed size, seed germination, and seedling survival of Brazilian tropical tree species differing in sucessional status. Biotropica, v.33, n.3, p.447-457, 2001.

SWAINE, M. D.; WHITMORE, T. C. On the definition of ecological species groups in tropical rain forests. Vegetatio, v.75, n.1, p.81-86, 1988.

TER BRAAK, C. J. F. Cannonical Correspondence Analysis: a new eigenvector technique for multivariate direct gradiente analysis. Ecology, v.67, n.5, p.1167-1179, 1986. 
VIEIRA, D. L. M.; SCARIOT, A. Principles of natural regeneration of tropical dry forests for restoration. Restoration Ecology, v.14, v.1, p.11-20, 2006.

WHITMORE, T. C. Canopy gaps and the two major groups of forest tree. Ecology, v.70, n.3, p.536-538, 1989.
WHITMORE, T. C. Tropical rain forest dynamics and its implications for management. In: GÓMEZPOMPA, A.; WHITMORE, T. C.; HADLEY, M. (Eds.) Rain forest regeneration and management. Park Ridge: The Parthenon Publishing Group, 1991. 457 p. (Man and the Biosphere Series, v. 6)

ZAR, J. H. Biostatistical analysis. Englewood Cliffs: Prentice-HaIl, 1999. 620 p. 